\title{
Dedicated system for design, analysis and optimization of AC-DC converters
}

\author{
S. PIASECKI ${ }^{1 *}$, R. SZMURLO ${ }^{2}$, J. RABKOWSKI $^{1}$, and M. JASINSKI ${ }^{1}$ \\ ${ }^{1}$ Institute of Control and Industrial Electronics, Warsaw University of Technology, 75 Koszykowa St., 00-662 Warsaw, Poland \\ ${ }^{2}$ Institute of Theory of Electrical Engineering, Measurement and Information Systems, Warsaw University of Technology, \\ 75 Koszykowa St., 00-662 Warsaw, Poland
}

\begin{abstract}
This paper presents an originally-developed system for design and optimization of AC-DC converters dedicated in particular to operation in distributed generation systems. The proposed procedure is based on a multi-objective discrete optimization and expert knowledge of electrical engineering, especially power electronics. The required accuracy of calculations is obtained by using the database with real components, while the parameters applied in calculations are based on parameters provided by the manufacturer. The paper presents the foundations and basic system properties, the design and optimization process, and selected optimization results, obtained with a fully functional prototype of the design and optimization system $(\mathrm{DaOS})$.
\end{abstract}

Key words: AC-DC converter, multi-objective optimization, design methodology, distributed generation systems.

\section{Introduction}

The three-phase, two-level AC-DC converter is a basic topology that performs $\mathrm{AC}$ to $\mathrm{DC}$, and also $\mathrm{DC}$ to $\mathrm{AC}$ energy conversion with possible bi-directional power flow. Nowadays, it is widely applied in adjustable speed drives, as a power electronics interface for renewable energy sources, energy storages and other active loads, generally called the distributed generation systems. The increasing number of distributed sources connected to the common grid requires the growing number of grid interfaces, such as AC-DC converters [1-3].

The selection process of the AC-DC converter design parameters has a decisive impact on the operation of the converter, quality of processed energy, realized functionalities, and the price of the system. High power quality, as well as high efficiency are required from power electronics converters used as grid interfaces. Moreover, a low price of the converter should be maintained - it means that conflicting design objectives need to be combined during the design and production process, what is schematically presented in Fig. 1.

To determine common dependencies between design parameters, and to find solutions for the contradictory design objectives, the optimization theory, which is known from economics, can be applied $[4,5]$. Implementation of multi-objective optimization methods into the design process of the AC-DC converter allows to increase the system's efficiency, reliability and functionality, and can further help to maintain the desired level of cost of the system. This approach is currently developed in many research centers around the world and reported by many authors [6-11].

In the presented work, multi-objective optimization is applied to assist the process of the AC-DC converter design, and it allows to find those design parameters, changing which would bring no

\footnotetext{
*e-mail: szymon.piasecki@ee.pw.edu.pl
}

benefit according to the assumed design criteria - the so-called Pareto optimum $[4,12]$. The developed optimization system, introduced in [13], allows for the analysis of how a change of one or more design variables will affect the system parameters and desired properties. The implementation of the proposed methodology enables this analysis to be performed in an early stage of the design process, giving the engineer a general overview of the available choices and possibilities.

The solution introduced in this work is dedicated for a twolevel voltage source converter (VSC) operating as an interface between a grid, and a distributed generation system called the grid-connected converter (GCC) [13, 14]. The selected optimization criteria (design objectives) for the GCC are the fundamental properties of this system: volume, efficiency, weight, power quality, and price. The optimization parameters are design variables: grid filter (type of the filter, values of elements, type of materials and elements used), type of power switches, cooling system, switching frequency, control algorithm (relevant in case

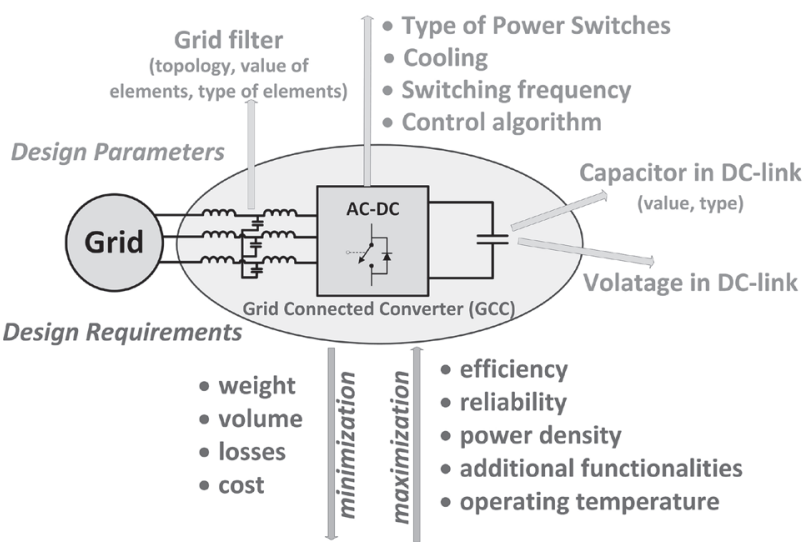

Fig. 1. Selected optimization criteria and parameters for a grid-connected AC-DC converter 


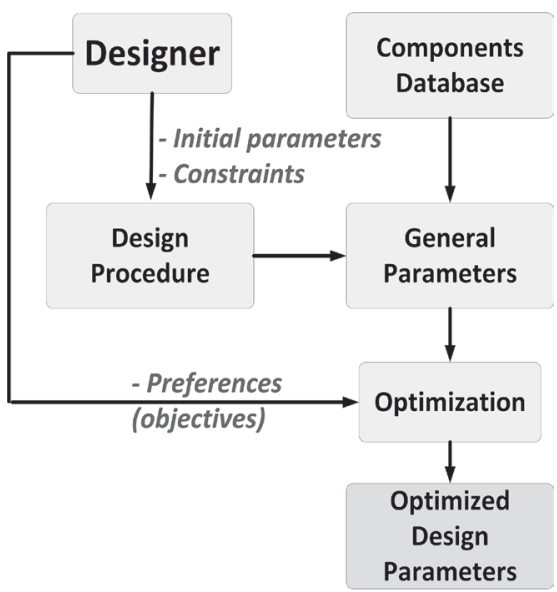

Fig. 2. Block diagram of the AC-DC converter parameters' selection and optimization methodology realized by the proposed $\mathrm{DaOS}$

of grid voltage distortion), DC-link capacitance, type of DC-link capacitor and DC-link voltage level (see Fig. 1).

This paper presents the concept and operation of the design-and-optimization procedure of a GCC. Moreover, selected results are presented to illustrate the system's operation and the performed optimization process. The proposed solution, called design and optimization system ( $\mathrm{DaOS})$, is dedicated for a grid-connected AC-DC converter, and is composed of three main elements: the procedure of the general parameters calculation (marked in Fig. 2 as design procedure), the database with parameters of real, commercially available GCC components: semiconductors, inductors, and capacitors (marked in Fig. 2 as components database), and finally, the optimization procedure, which includes evolutionary algorithms. The DaOS has been introduced in [13], while in the presented work, a more detailed description and extended results are presented. Each element of the proposed concept of selection and optimization of GCC parameters, presented in Fig. 2, is described in detail in the following sections.

\section{Grid-connected converter - calculation of general parameters}

The first stage of the proposed methodology is the calculation of the general design parameters of the GCC based on the initial conditions specified by the designer, as shown in Figs. 3, 4. A screen capture of the $\mathrm{DaOS}$ with the window for the specification of initial parameters is presented in Fig. 3. As the initial conditions, the designer specifies: nominal power of the system $\left(P_{N}\right)$, nominal grid voltage $\left(U_{G R I D}\right)$, grid frequency $\left(f_{G}\right)$, allowed DC-voltage ripples $\left(\triangle \mathrm{U}_{D C}\right)$, type of the analyzed grid filter $(L C L, L C L+$ Trap, $L L C L$ ) and its damping properties (the allowed ripple current on the converter-side inductor, expressed as a percentage of the nominal current - RippC, a percentage ratio of the inductance of the grid-side inductor to the converter-side inductor - SplitR, and the maximum reactive power absorbed by the filter $-Q_{L C L}$, also expressed as a percentage of nominal power). Moreover, the designer defines the range and step of changes for the two main variables used in calculations: switching frequency $\left(f_{s w}\right)$ and DC-link voltage $\left(U_{D C}\right)$. Based on these values for specific $f_{s w}$ and $U_{D C}$, general design parameters of the GCC, such as values of the filter elements $\left(L_{C}, L_{G}, C_{L C L}\right)$, the resonant frequency of the filter $\left(f_{R E S O}\right)$, DC-cir-

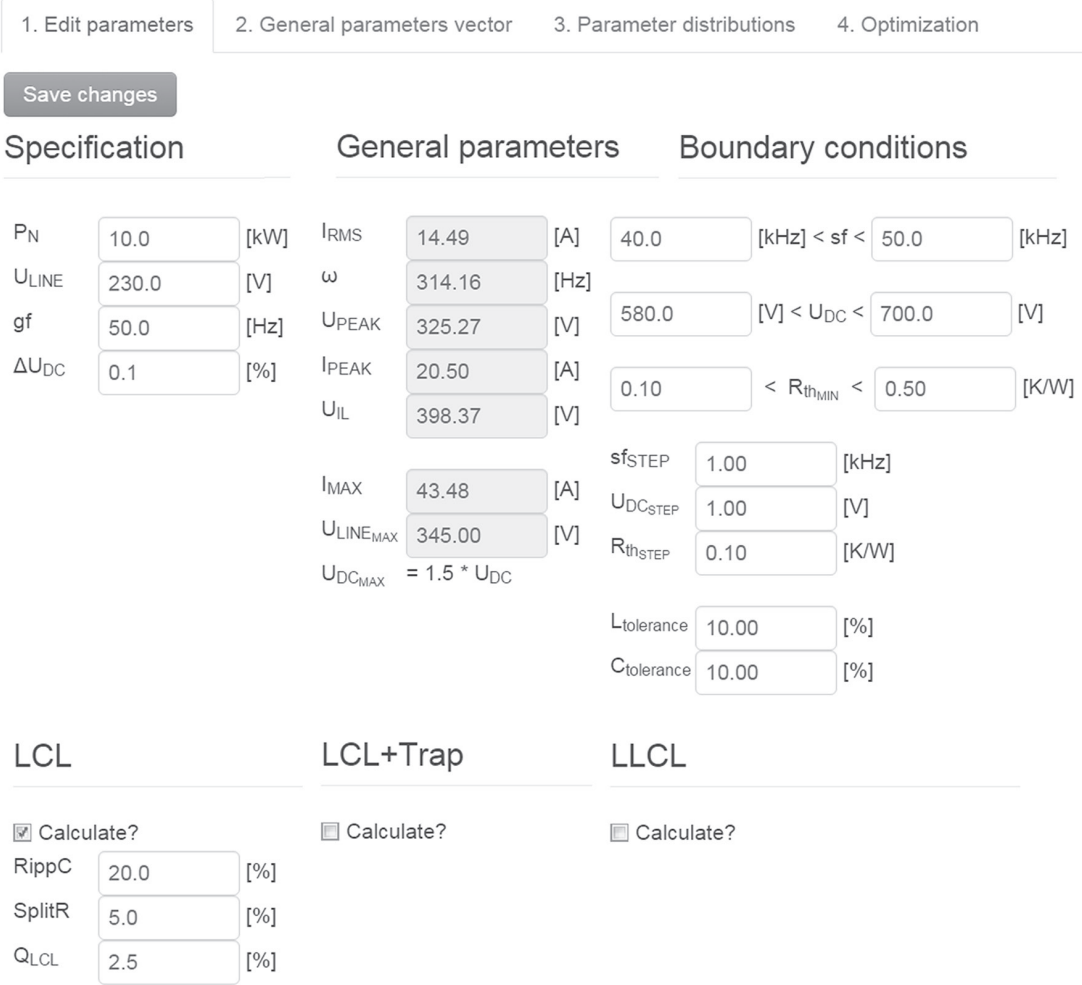

Fig. 3. Screen capture of the developed design and optimization system for the grid-connected converter parameters 


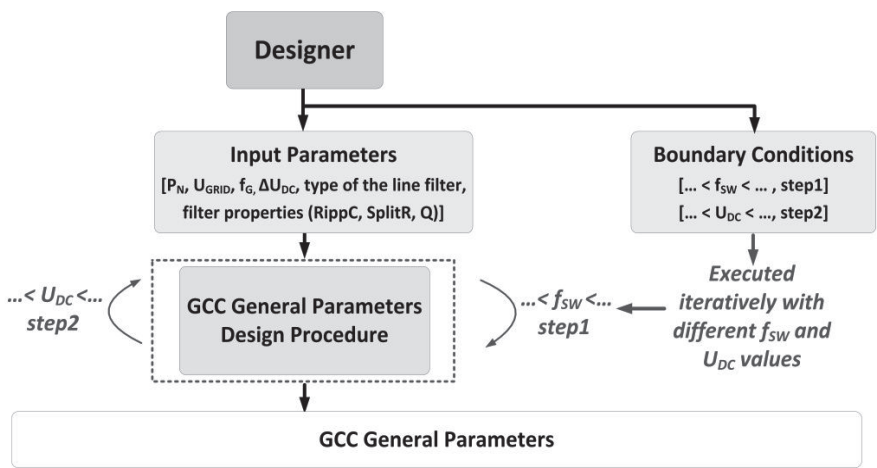

Fig. 4. Operation of the calculation of AC-DC converter's general design parameters - block scheme

cuit capacitance $\left(C_{D C}\right)$, and a series of auxiliary parameters, are determined.

The calculation of the general parameters of the GCC is performed iteratively with the changing values of $f_{s w}$ and $U_{D C}$, with each set of calculated parameters being saved as a single vector in the matrix of the converter's general parameters. The methodology of determining the general system parameters is described in detail in [16-18], and the operation of the procedure is shown in Fig. 4.

\section{The components database}

The second element of the presented DaOS is a database of real, commercially available system components. To reduce the optimization calculations and to speed up the design process (by omitting the feasibility study proposed in $[6,19,20])$, estimations in the developed procedure are restricted to the real, commercially available components. The database consists of three groups of components:

- Power semiconductors - in this group there are the implemented power transistors, both IGBTs and MOSFETs. Each transistor is implemented as a separate record in the database, and the data used for the calculations are based on the datasheets provided by the manufacturer. In the first version of the system, the freewheeling diode is omitted, and the calculations are focused on the transistor as a primary source of losses and costs.

- Inductors - this group contains the parameters of the inductors. In the first version, in calculations the system uses the parameters of the available, existing inductors. The parameters of the inductors are based on the manufacturer's datasheets or laboratory measurements. Each inductor in the database is implemented as a separate record.

- Capacitors - the last element of the database are the capacitors, also with parameters based on catalogue information. Capacitor calculations are performed for the DC-link and grid filter capacitors.

The database of proposed elements allows the designer to view the properties of the individual components and select those which need to be considered during execution of a particular optimization (e.g. are currently in the company's warehouse).

Furthermore, by defining the appropriate parameters in the database, the parallel connection of converter components, such as power transistors or capacitors, may also be accounted for in the optimization process.

\section{The optimization procedure}

The last element, which integrates all components of the proposed system, is the optimization procedure. In order to use discrete optimization methods, the entire system, that is the database of the system components, the design parameters, and the optimization process, have a discrete character. Both the design variable vectors stored in the general parameters matrix and the component parameters stored in the database are discrete values. Thus, it is possible to apply the discrete evolutionary optimization algorithms [9, 20-22]

The optimization parameters are the main design variables: switching frequency $\left(f_{s w}\right)$, DC-link voltage level $\left(U_{D C}\right)$, type of the grid filter and values of the filter components $\left(L_{C}, L_{G}, C_{L C L}\right)$, specific inductors (matched and selected from the database), power semiconductor (type, specific model, and the possible number of devices connected in parallel as a single switch - based on the database), thermal resistance of the heatsink $\left(R_{T H}\right)$, DC-circuit capacitance $\left(C_{D C}\right)$, and the type of DC-link capacitor (based on the database). For the developed procedure and performed calculations, both the electric variables (DC voltage level, switching frequency) and the physical properties of the system (type of the capacitor, inductor, etc.) are considered the optimization parameters.

Expectations related to the design, here defined as optimization criteria (objectives), are expressed by related performance indices. According to [6], the following performance indices can be used for the discussed power electronics converters:

- Efficiency of the system, expressed by:

- Overall efficiency:

$$
\eta=\frac{P_{O}}{P_{I}}[p . u .]
$$

where $P_{O}$ - output power, $P_{I}$ - input power;

- Relative losses:

$$
\frac{P_{L}}{P_{O}}=\frac{1-\eta}{\eta}[p . u .]
$$

where $P_{L}$ - system losses, $P_{O}$ - output power, $\eta$ - efficiency;

- Losses, expressed as summarized losses of GCC components.

- Power quality of the processed energy, expressed by AC-side current / voltage THD factors $\left(I_{T H D} / U_{T H D}\right)$

- Volume/Weight of the system, expressed by:

$\circ$ Power Density Factor $(\rho)$ :

$$
\rho=\frac{P_{O, N}}{V_{G}}\left[\frac{k W}{d m^{3}}\right],
$$

where $P_{O, N}$ - rated output power, $V_{G}-$ overall volume of the system;

- Inversed Power Density Factor $(1 / \rho)$;

- Output Power per Unit Weight $(\gamma)$ :

$$
\gamma=\frac{P_{O}}{W_{G}}\left[\frac{k W}{k g}\right],
$$

where $P_{O}$ - output power, $W_{G}$ - overall weight of the system; 
- Price of the system, expressed by Relative Costs $(\sigma)$ :

$$
\sigma=\frac{P_{O}}{C_{I}}\left[\frac{k W}{\$}, \frac{k W}{€}\right],
$$

where the output power $P_{O}$ is installed for the incurred cost $C_{I}$.

In some design approaches, the performance index can be expressed as a constraint, which is a limit for a selected objective maximal or minimal value, specified by the designer [5, 23].

In the proposed design-and-optimization methodology, the following performance indices have been used: volume $(V)$, weight $(W)$, losses (Loss.), and price (\$). The aim of the optimization process is to minimize selected performance indices. In addition, the importance of individual criteria (expressed by the corresponding indicators) is determined by the weighting coefficients in the global cost function.

The process of the design and optimization of the GCC parameters, presented schematically in Fig. 5, is realized as follows:

a. The designer sets the initial conditions: the nominal power, voltage and frequency, the acceptable level of DC-voltage fluctuations (expressed as a percentage of the nominal DClink voltage level) - a window with the declaration of these parameters is shown in Fig. 3. In addition, the system calculates several auxiliary parameters (such as the maximal and average currents and voltages, etc.).

b. The designer specifies the boundary conditions for the performed calculations, that is the analyzed range of changes for the three design variables: switching frequency, DC-link voltage level, and thermal constant of the heatsink. Moreover, the designer specifies the step of changes for particular values, which corresponds to the density of calculations. Thus, for example, the designer may determine the $U_{D C}$ voltage changes to be in a range of $600-750 \mathrm{~V}$ with a $5 \mathrm{~V}$ step.

c. In the next step, the designer determines what type of grid filter should be analyzed during the calculations ( $L C L$, $L C L+$ Trap, $L L C L$ ) [16], and it is possible to simultaneously analyze all the included types of filters, or only the selected ones.

d. The last variables specified by the designer are the damping characteristics of the grid filter, expressed by coefficients described above. Based on predefined parameters, the system generates a number of vectors containing the general parameters of the AC-DC grid interface (for particular values of $U_{D C}$ and $f_{s w}$ ).

e. The next step of the calculation is the optimization of the design parameters. The designer can select an evolutionary algorithm (in the developed DaOS there are 5 algorithms available: NSGAIII, OMOPSO, eMOEA, SPEA2, and SMPSO [20, 24-28]) and preferences for individual criteria by selecting the weighting coefficients in the objective function.

On the basis of the component parameters (stored in the database) and implemented calculation scripts, for each individual combination of general parameters vector and real components from the database, a set of local performance indices (LPIs) is obtained (see Fig. 5). Then, the LPIs are combined together and evaluated, taking into account the weights of the individual criteria provided by the designer:



Fig. 5. Block scheme of the AC-DC converter parameter design-and-optimization process realized by the proposed $\mathrm{DaOS}$

$P I_{\text {Volume }}=\left(\alpha_{\text {ind. }} \cdot V_{\text {ind. }}+\alpha_{\text {sem. }} \cdot V_{\text {sem. }}+\alpha_{\text {cap. }} \cdot V_{\text {cap. }}\right)$

$P I_{\text {Losses }}=\left(\alpha_{\text {ind. }} \cdot\right.$ Loss. $_{\text {ind. }}+\alpha_{\text {sem. }} \cdot$ Loss $_{\text {sem. }}+\alpha_{\text {cap. }} \cdot$ Loss $\left._{\text {cap. } .}\right)$

$P I_{\text {Weight }}=\left(\alpha_{\text {ind. }} \cdot W_{\text {ind. }}+\alpha_{\text {sem. }} \cdot W_{\text {sem. }}+\alpha_{\text {cap. }} \cdot W_{\text {cap } .}\right)$

$P I_{\text {Price }}=\left(\alpha_{\text {ind. }} \cdot \$_{\text {ind. }}+\alpha_{\text {sem. }} \cdot \$_{\text {sem. }}+\alpha_{\text {cap. }} \cdot \$_{\text {cap. }}\right)$,

where $\alpha_{\text {ind. }}, \alpha_{\text {sem. }}$, and $\alpha_{\text {cap }}$ are weighting coefficients for particular components of the system (inductor, semiconductor, and capacitor), while volume $(V)$, losses (Loss.), weight $(W)$ and price $(\$)$ are performance indices.

Various combinations of GPVs and real components are obtained based on evolutionary algorithm operation (see Figs. 5, 6).

\section{The evolutionary algorithms}

To realize multi-objective optimization calculations, evolutionary algorithms (EA) are implemented. The EA use mechanisms inspired by biological evolution, such as reproduction, mutation, recombination, and selection $[4-5,29]$. The idea for all EA techniques is to select from a given population the fittest individuals, as in natural selection (survival of the fittest). The selection is carried out on the basis of given criteria (here - cost function), and the measure of the fittest are the quality indicators, in this particular case, the performance indices. 
The whole optimization process is based on populations which evolve during generations (selection of the fittest individuals). In each generation, the individuals of the population are evaluated according to the established criteria. The fittest are selected to the next generation, and create a new population. The new population is subjected to evolution (evolutionary operations, e.g. mutation, crossover), and the whole process is repeated until the termination conditions are fulfilled. A flow chart of this process is presented in Fig. 6.

Each individual from the population represents a single decision vector, for which the values of cost functions $f_{i}(x)$ are evaluated. To obtain a Pareto front as a final result of MOO, only nondominated individuals are promoted for the next generation. After the $n$-th generation, the obtained population should represent the approximation of the Pareto front. To promote non-dominated solutions, a Pareto-based ranking scheme should be applied. The simple approach can convert a multi-objective problem with respect to objectives $f_{i}(x)$ into a scalar one, by defining a single formula allowing to assess the quality of solution $x^{*}[29]$ :

$$
\min _{x \in \mathbf{X}, \delta \geq 0} \sum_{i=1}^{k} \delta_{i} \text {, subject to } \mathrm{f}_{i}(x)+\delta_{i}=f_{i}\left(x^{*}\right), i=1,2, \ldots, k \text {. }
$$

The vector $\mathrm{x}^{*}$ is Pareto-optimal when all $\delta_{i}$ are equal to zero [29]. For the evolutionary algorithm, the full set of feasible solutions $\in \mathrm{X}$ can be replaced with a set of vectors from the current generation.

The disadvantage of EAs is the necessity of evaluation of the cost functions for usually large populations and a large number of

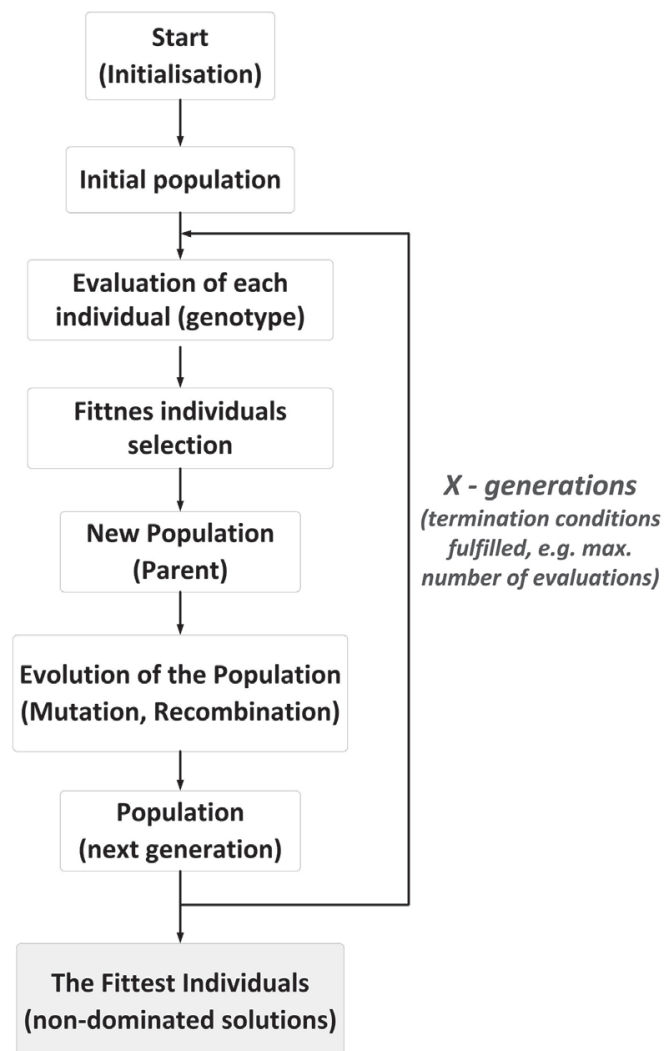

Fig. 6. Flow chart of the optimization process based on evolutionary algorithm generations. However, the EA are the most appropriate for discrete problem optimization. An efficient implementation of such an algorithm should consider the analysis to select optimal parameters for elitism, crossover, population size, and number of generations best suited for a given application. In this work the nondominated sorted genetic algorithm III (NSGAIII), strength Pareto evolutionary algorithm 2 (SPEA2) and particle swarm optimization algorithms (eMOEA, OMOPSO, SMOPSO) are analysed [29-30].

\section{Implementation of the design-and-optimization system}

The proposed design and optimization system (DaOS) was developed as a web application. This ensures easy access to the current version of the application and the ability to expend significant hardware resources. The application was implemented in the Java language using Grails framework. Scripts for the calculation of the general parameter vectors and values of local performance indices related to the selected components of the system run on separate processes in parallel, in the GNU Octave computing environment. The system runs on a virtual machine based on Linux Ubuntu, and has 8 virtual processors (Intel Xeon X5460) clocked at $3.16 \mathrm{GHz}$ and 4 GB of RAM allocated. The database of components, sets of general parameter vectors, and obtained Pareto-optimal results use the MySQL database server on the same machine. The evolutionary algorithms to determine the Pareto front are implemented from the MOEA framework library [31]. The selected optimization algorithm is executed with a designer-specified size of the population $(m)$, and a maximum number of evaluations of the objective function $(n)$ performed during the calculation of the EA.

\section{Results of the optimization process}

7.1. Verification of the optimization algorithm operation. Proper operation and performance of the proposed DaOS and selected optimization algorithms has been verified through a series of analyses, and by comparison of the obtained results with the reference. For evaluation of the $n$-dimensional Pareto front, quality indicators: Spacing, Generational Distance, Hyper Volume, and Elapsed Time are employed. The meaning of the particular indicators illustrated in Fig. 7 is as follows:

- Spacing (SP) - this indicator gives information on how evenly the results are distributed along the known Pareto front;

- Hyper Volume (HV) - this indicator gives information about the volume (in the objective space) covered by a non-dominated set of solutions for a problem where all objectives need to be minimized. Bigger values of the HV indicator are required;

- Generational Distance (GD) - this indicator gives information on how far (on average) the obtained results are from a true Pareto front. A value of GD equal to zero indicates that all calculated elements are on the true Pareto front;

- Elapsed Time - time calculated from the beginning of the optimization process. 


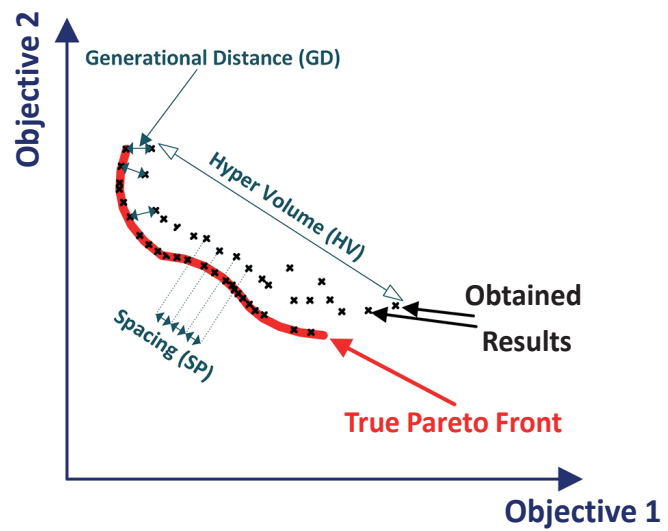

Fig. 7. Pareto front quality indicators used for the evaluation of the optimization results - two-objective (2-dimensional) representation
The problem in this case is how to achieve a "true Pareto front" (reference result) used in evaluation of the algorithms. Usually, for problems with a huge number of possible choices, where calculation of all possibilities in finite time is impossible, the reference result is obtained by execution of the selected optimization algorithm with a huge number of evaluations (e.g. 100 000).

In order to verify the correct operation of the proposed DaOS, a test components database has been created. The database contains 300 records of semiconductors, 300 records of inductors, and 300 records of capacitors. With 16426 possible GPVs generated, it gives (8):

$$
16426_{G P V} \cdot 300_{\text {Semic. }} \cdot 300_{\text {Ind. }} \cdot 300_{\text {Cap. }}=4.43 \cdot 10^{11}
$$

possible combinations. In this case, the reference result has been obtained with 100000 evaluations of the NSGAIII algorithm with the initial population equal to 50. In the case of the discussed $\mathrm{DaOS}$, calculation of the reference result takes 6 hours. Perfor- a)

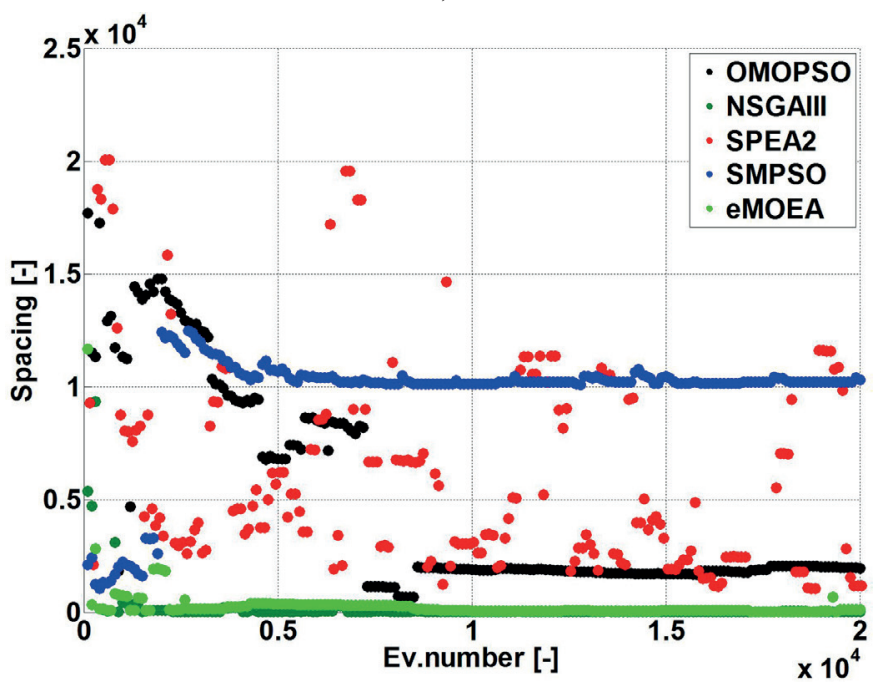

c)

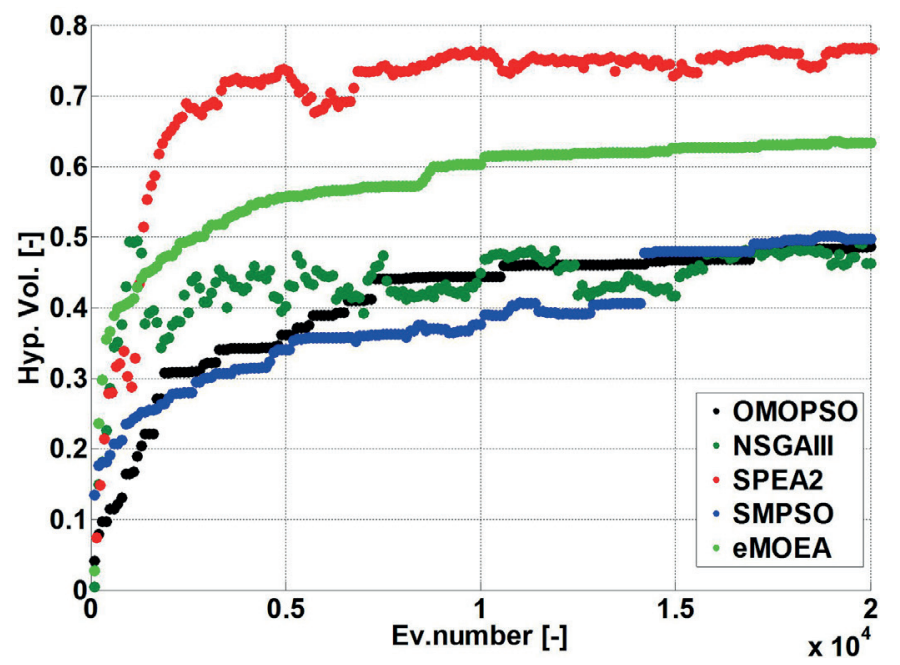

b)



d)

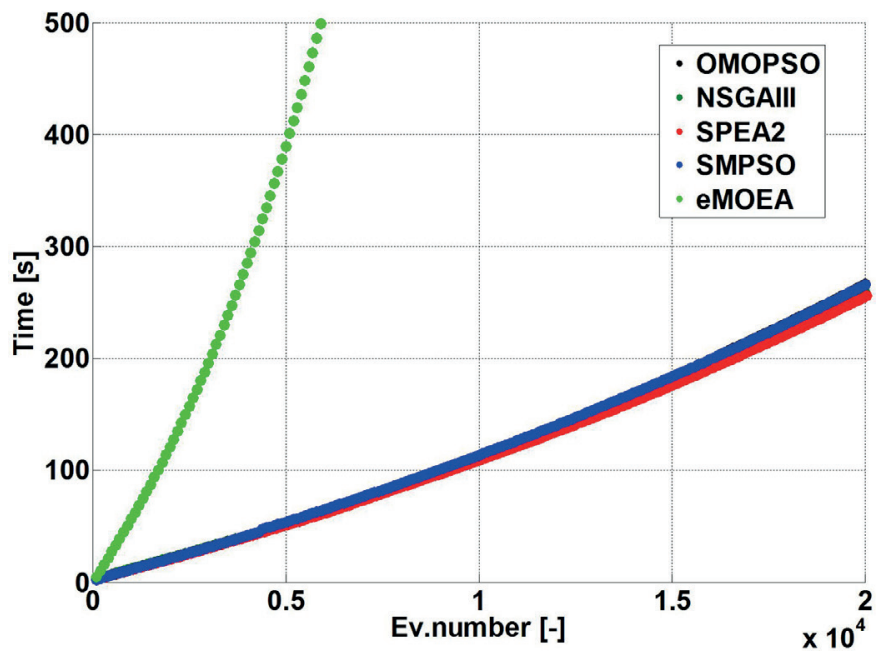

Fig. 8. Performance of the optimization algorithms. The quality indicators of the optimization results obtained with the evaluation number equal to 20000 for 5 analyzed evolutionary algorithms with initial population equals 50. a) Spacing indicator, b) Generational Distance indicator, c) Hyper Volume indicator, d) time of calculations, all versus the number of evaluations (Ev. Number) 


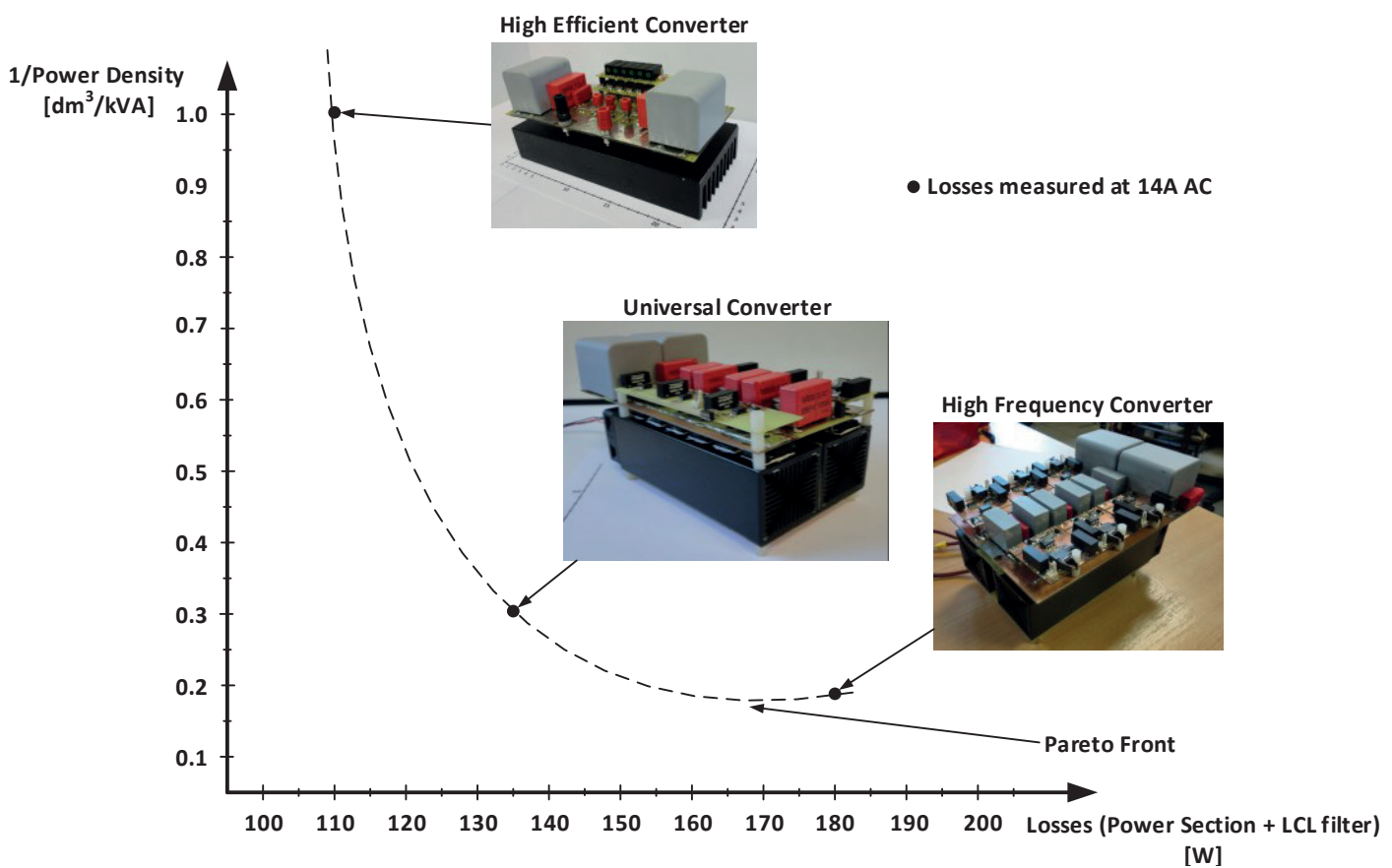

Fig. 9. The 2D performance space-and-optimization criteria selected for the designed laboratory prototypes based on SiC power devices

mance of the analysed optimization algorithms (NSGAIII, SPEA2, OMOPSO, SMPSO, eMOEA), expressed by particular quality indicators, is illustrated in Fig. 8. As it can be observed in the Fig. 8 , for a relatively high number of possible combinations $\left(4.43502 * 10^{11}\right), 20000$ evaluations of the cost function are sufficient to find the results close to the reference (Pareto optimal). From the analysed algorithms, the NSGAIII, eMOEA, and SMPSO have the best performance, however, due to the short computation time, the NSGAIII and SMPSO are selected as the best ones for the discussed issue.

7.2. Application of proposed methodology. The proposed design-and-optimization methodology was applied to the design of the three laboratory prototypes with a nominal power of $10 \mathrm{kVA}$.
Each converter has been designed with different requirements related to volume and efficiency objectives with implementation of the presented DaOS. The High Efficient Converter was designed to achieve the highest possible efficiency (with the LCL filter). The Universal Converter was designed as a compromise between efficiency maximization and volume minimization. Finally, the High Frequency Converter was designed to achieve the highest power density. An additional assumption was that only $\mathrm{SiC}$ power switches are considered for the models. Detailed design parameters of the converters can be found in [18, 32-34]. The experimentally-obtained 2D Pareto front with a view of the prototypes is presented in Fig. 9. Experimentally measured losses and efficiency characteristics of the prototypes, obtained with the use of a Yokogawa WT1806 power analyzer, are presented in Fig. 10, while
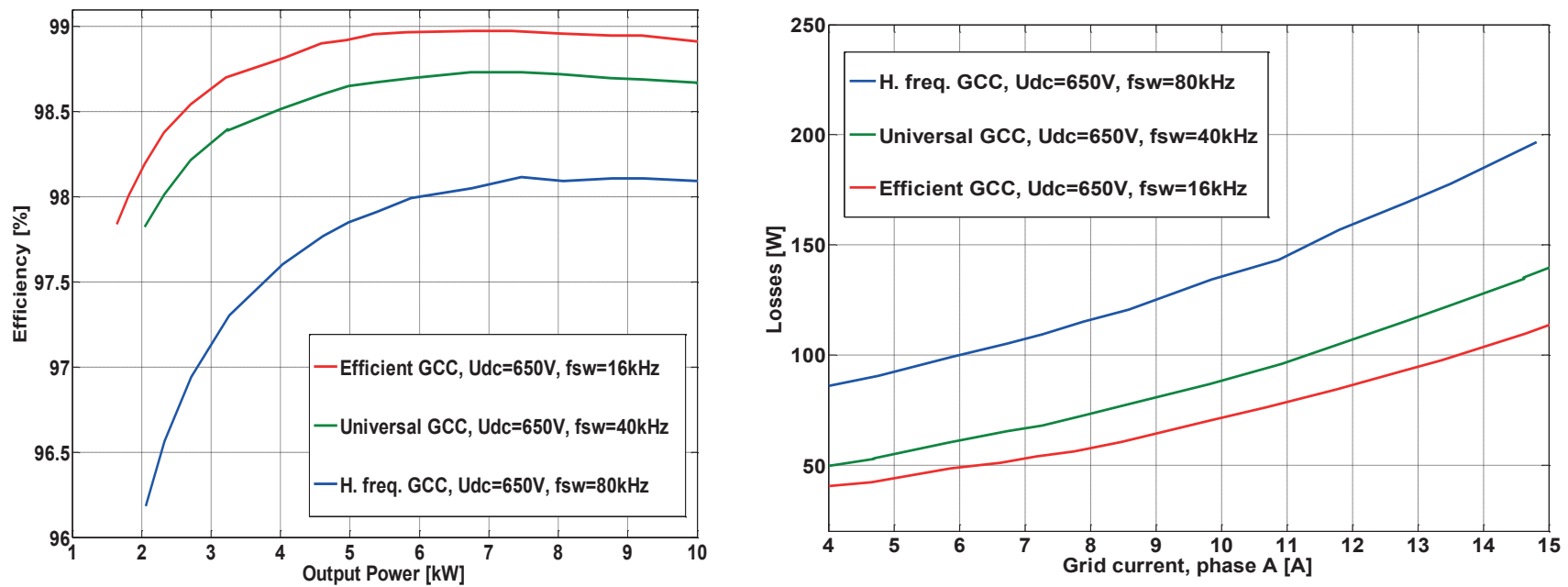

Fig. 10. Experimentally measured efficiency and power losses of the designed laboratory prototypes, versus output power. Converters operate as active rectifiers, supplying a DC load 
Table 1

Parameters of the designed laboratory prototypes based on SiC power devices

\begin{tabular}{|c|c|c|c|}
\hline Parameter & High Efficient & Universal & High Frequency \\
\hline Rated Power & $10[\mathrm{kVA}]$ & $10[\mathrm{kVA}]$ & $10[\mathrm{kVA}]$ \\
\hline AC Nominal Voltage & 230 [V RMS] & 230 [V RMS] & 230 [V RMS] \\
\hline AC Nominal Current & 14.5 [A RMS] & 14.5 [A RMS] & 14.5 [A RMS] \\
\hline DC Nominal Voltage & $580-700[\mathrm{~V} \mathrm{DC}]$ & $580-700[\mathrm{~V} \mathrm{DC}]$ & $580-700[\mathrm{~V} \mathrm{DC}]$ \\
\hline DC Nominal Current & $14.3-17.3[\mathrm{~A} \mathrm{DC}]$ & $14.3-17.3[\mathrm{~A} \mathrm{DC}]$ & $14.3-17.3[\mathrm{~A} \mathrm{DC}]$ \\
\hline Switching Frequency & $16-24[\mathrm{kHz}]$ & $40[\mathrm{kHz}]$ & $80[\mathrm{kHz}]$ \\
\hline Line Filter Type & LCL & LCL & LCL \\
\hline Line Filter Parameters & $\begin{array}{c}\text { For } \mathrm{f}_{\mathrm{SW}}=16[\mathrm{kHz}] \\
\mathrm{L}_{\text {Conv }}=1.5[\mathrm{mH}] \\
\mathrm{C}_{\mathrm{LCL}}=5[\mu \mathrm{F}] \\
\mathrm{L}_{\text {Grid }}=100[\mu \mathrm{H}]\end{array}$ & $\begin{array}{c}\text { For } \mathrm{f}_{\mathrm{SW}}=40[\mathrm{kHz}] \\
\mathrm{L}_{\text {Conv }}=250[\mu \mathrm{H}] \\
\mathrm{C}_{\mathrm{LCL}}=5[\mu \mathrm{F}] \\
\mathrm{L}_{\text {Grid }}=100[\mu \mathrm{H}]\end{array}$ & $\begin{array}{c}\text { For } \mathrm{f}_{\mathrm{SW}}=80[\mathrm{kHz}] \\
\mathrm{L}_{\text {Conv }}=250[\mu \mathrm{H}] \\
\mathrm{C}_{\mathrm{LCL}}=5[\mu \mathrm{F}] \\
\mathrm{L}_{\text {Grid }}=100[\mu \mathrm{H}]\end{array}$ \\
\hline DC-link capacitance & $162[\mu \mathrm{F}]$ & $100[\mu \mathrm{F}]$ & $118[\mu \mathrm{F}]$ \\
\hline Power devices & CCS050M12CM2 & $\begin{array}{l}6 \times \mathrm{C} 2 \mathrm{M} 0025120 \mathrm{D} \\
6 \times \mathrm{C} 4 \mathrm{D} 20120 \mathrm{D}\end{array}$ & $\begin{array}{c}12 \times \mathrm{C} 2 \mathrm{M} 0080120 \mathrm{D} \\
6 \times \mathrm{C} 4 \mathrm{D} 20120 \mathrm{~A}\end{array}$ \\
\hline Heatsink & $\begin{array}{c}1 \times \text { Fisher SK92 } 220 \mathrm{~mm} \\
\quad\left(\mathrm{R}_{\mathrm{TH}}=0.9 \mathrm{~K} / \mathrm{W}\right)\end{array}$ & $\begin{array}{c}2 \times \text { Fisher LAM-5-150 } \\
\left(\mathrm{R}_{\mathrm{TH}}=0.25^{\circ} \mathrm{C} / \mathrm{W}\right)\end{array}$ & $\begin{array}{c}2 \times \text { Fisher LAM-5-150 }\left(\mathrm{R}_{\mathrm{TH}}=0.25^{\circ} \mathrm{C} / \mathrm{W}\right) \\
\text { with air forced cooling }\end{array}$ \\
\hline Power Density Factor (with LCL) & $0.94\left[\mathrm{~kW} / \mathrm{dm}^{3}\right]$ & $3.16\left[\mathrm{~kW} / \mathrm{dm}^{3}\right]$ & $5.23\left[\mathrm{~kW} / \mathrm{dm}^{3}\right]$ \\
\hline Weight (with LCL) & $15.7[\mathrm{~kg}]$ & $5.24[\mathrm{~kg}]$ & $5.45[\mathrm{~kg}]$ \\
\hline Cost (with LCL) & $946[€]$ & $1093[€]$ & $953[€]$ \\
\hline Peak Efficiency (with LCL) & $99.1 \%$ & $98.8 \%$ & $98.2 \%$ \\
\hline
\end{tabular}

parameters of the prototypes are collected in Table 1. The developed Universal and High Frequency prototypes have the same grid filter parameters according to the EMI issue and necessity of minimization of the generated distortion.

\section{Summary and conclusions}

The paper presents an originally developed system for the design and optimization of an AC-DC grid-connected converter (GCC), calledthe design and optimization system (DaOS).

The essential features of the proposed system are:

- Universality and simplicity - various blocks of the system communicate with each other and share their calculation results. Design and optimization calculations are performed using computational scripts, which can be freely modified, depending on the designer's needs. By providing a dedicated, easy for modification script for calculation of the general system parameters (the grid filter elements, DC-link voltage level, DC circuit capacity, and switching frequency), the introduced tool is general in nature and universal.

- Flexibility - the procedure is based on the authors' knowledge and experience in the field of the design of power electronics converters, and is represented in the form of mathematical equations. It is possible to perform any modifications of the script to achieve the desired properties of the system, adjust calculations for a particular topology, or change a particular control algorithm on the fly, without any required assistance from software developers.

- High calculation speed and performance - the system employs evolutionary algorithms, which provide a high performance and speed of the optimization process. To achieve more accurate results of the calculations, the scripts used for the local performance indices calculation can be extended. Conversely, to accelerate the computation time, the scripts may be simplified to speed up the calculations. The scripts analyzed in the work are a compromise between calculation time and accuracy, allowing to obtain satisfying results used in the optimization process in a relatively short period of time.

The obtained results were calculated with the fully functional prototype of the presented system. The presented results are preliminary, demonstrating the concept and possibilities of the proposed system and its operation principles.

Acknowledgments. This work has been supported by the National Science Center, Poland, based on decision DEC-2012/05/B/ ST7/01183 and partially supported the statutory activities of the Department of Industrial Electronics (Warsaw Univ. of Technology). 


\section{REFERENCES}

[1] R. Teodorescu, M. Liserre, and P. Rodriguez, Grid Converters for Photovoltaic and Wind Power Systems, John Wiley \& Sons, Inc., 2011.

[2] L.L. Grigsby, Electric Power Generation, Transmission, and Distribution. The Electric Power Engineering Handbook, 3rd ed., CRC Press, 2012.

[3] J.W. Kolar, T. Friedli, J. Rodriguez, and P.W. Wheeler, "Review of three-phase PWM AC-AC converter topologies", IEEE Trans. Ind. Electron. 58 (11), 4988-5006 (2011).

[4] V. Chankong and Y.Y. Haimes, Multiobjective Decision Making: Theory and Methodology, North-Holland, Amsterdam, 1983.

[5] J. Branke, K. Deb, K. Miettinen, and R. Słowiński, "Multiobjective Optimization, Interactive and Evolutionary Approaches", Springer, 2008.

[6] J. W. Kolar, J. Biela, S. Waffler, T. Friedli, and U. Badstuebner, "Performance trends and limitations of power electronics systems", 6th International Conference on Integrated Power Electronics Systems (CIPS 2010), 1-20 (2010).

[7] C. Larouci, M. Boukhnifer, and A. Chaibet, "Design of power converters by optimization under multiphysic constraints: Application to a two-time-scale AC/DC-DC converter", IEEE Trans. Ind. Electron. 57 (11), 3746-3753 (2010).

[8] N. Froehleke, D. Hahm, H. Mundinger, H. Njiende, P. Wallmeier, and H. Puder, "CAE-tool for optimizing development of switched mode power supplies", Sixteenth Annual IEEE Applied Power Electronics Conference and Exposition (APEC 2001) 2, 752-758 (2001).

[9] B.Y.S. Busquets-Monge, G. Soremekun, E. Hertz, C. Crebier, S. Ragon, D. Boroyevich, Z. Gürdal, M. Arpilliere, and D.K. Lindner, "Power converter design optimization. A GA-based design approach to optimization of power electronics circuits", IEEE Ind. Appl. Mag. 10 (1), 32-39 (2004).

[10] S. Koziel and A. Bekasiewicz, "Recent developments in simulation-driven multi-objective design of antennas", Bull. Pol. Ac.: Tech. 63 (3), 781-789 (2015).

[11] M.B. Gorzałczany and F. Rudziński, "Handling fuzzy systems" accuracy-interpretability trade-off by means of multi-objective evolutionary optimization methods - selected problems", Bull. Pol. Ac.: Tech. 63 (3), 2015

[12] R.T. Marler and J.S. Arora, "Survey of multi-objective optimization methods for engineering", Struct. Multidiscip. Optim. 26 (6), 369-395 (2004).

[13] S. Piasecki, M.P. Kaźmierkowski, R. Szmurło, J. Rąbkowski, "System doboru i optymalizacji parametrów przekształtnika sieciowego AC-DC", in Proc. of XII Konferencja Naukowa Sterowanie w Energoelektronice i Napędzie Elektrycznym (SENE 2015), 18-20 (2015), [in Polish].

[14] R.C. Dugan, T.S. Key, and G.J. Ball, "Distributed resources standards", IEEE Ind. Appl. Mag. 12 (1), 27-34 (2006).

[15] M.P. Kazmierkowski, R. Krishnan, and F. Blaabjerg, Control in Power Electronics. Selected Problems, Academic Press, 2002.

[16] S. Piasecki, R. Szmurlo, and M. Jasinski, "Design of AC-DC grid vonnected vonverter using multi-objective optimization", Electr. Control Commun. Eng. 5 (1), 11-19 (2014).

[17] S. Piasecki, "High order line filters for grid vonnected AC-DC vonverter - Parameters selection and optimization", in IEEE 23rd International Symposium on Industrial Electronics (ISIE), 2691-2696 (2014).
[18] S. Piasecki, "Research and development of multi-objective optimization procedures for AC-DC grid converters, in particular for renewable/distributed energy systems", PhD Thesis, Warsaw University of Technology, 1-227 (2016).

[19] J.W. Kolar, U. Drofenik, J. Biela, M.L. Heldwein, H. Ertl, T. Friedli, and S.D. Round, "PWM converter power density barriers", Power Conversion Conf. (PCC'2007), 9-29 (2007).

[20] J.W. Kolar, J. Biela, and J. Minibock, "Exploring the Pareto front of multi-objective, single-phase PFC rectifier design optimization - $99.2 \%$ efficiency vs. $7 \mathrm{~kW} / \mathrm{din} 3$ power density", 6th International Power Electronics and Motion Control Conference (IPEMC), 1-21 (2009).

[21] K. Deb and H. Jain, "An evolutionary many-objective optimization algorithm using reference-point-based nondominated sorting approach, part I: Solving problems with box constraints", IEEE Trans. Evol. Comput. 18 (4), 577-601 (2014).

[22] R.R. Chan, S.D. Sudhoff, Y. Lee, and E.L. Zivi, "Evolutionary optimization of power electronics based power systems", 22nd Annual IEEE Applied Power Electronics Conference and Exposition (APEC 2007), 449-456 (2007).

[23] E. Zitzler, M. Laumanns, and S. Bleuler, "A Tutorial on evolutionary multiobjective optimization", in Metaheuristics for Multiobjective Optimisation, pp. 3-37, eds. X. Gandibleux, M. Sevaux, K. Sörensen, and V. T'kindt, Springer, Berlin, 2004.

[24] C. Larouci, "Pre-sizing of power converters using optimization under constraints", IEEE International Conference on Industrial Technology (ICIT), 1-6 (2008).

[25] H. Jain and K. Deb, "An evolutionary many-objective optimization algorithm using reference-point-based nondominated sorting approach, part II: Handling constraints and extending to an adaptive approach", IEEE Trans. Evol. Comput. 18 (4), 602-622 (2014).

[26] M. Reyes Sierra and C.A. Coello Coello, "Improving PSO-based multi-objective optimization using crowding, mutation and e-dominance", in Evolutionary Multi-Criterion Optimization, pp. 505519, eds. C.A. Coello Coello, A. Hernández Aguirre, and E. Zitzler, Springer, Berlin, 2005.

[27] K. Deb, M. Mohan, and S. Mishra, "A fast multi-objective evolutionary algorithm for finding well-spread Pareto-optimal solutions", 2003.

[28] M.L.L.T. Eckart Zitzler, "SPEA2: Improving the strength Pareto evolutionary algorithm”, 2001.

[29] E. Zitzler, M. Laumanns, and S. Bleuler, "A tutorial on evolutionary multiobjective optimization", in Metaheuristics for Multiobjective Optimisation, pp. 3-37, eds. X. Gandibleux, M. Sevaux, K. Sörensen, and V. T'kindt, Springer, 2004.

[30] A.J. Nebro, J.J. Durillo, J. Garcia-Nieto, C.A. Coello Coello, F. Luna, and E. Alba, "SMPSO: A new PSO-based metaheuristic for multi-objective optimization", 2009 IEEE Symposium on Computational Intelligence in Milti-Criteria Decision-Making, 66-73 (2009).

[31] D. Hadka, "MOEA framework user guide", 2014.

[32] S. Piasecki, J. Rabkowski, G. Wrona, and T. Platek, "SiC-based support converter for passive front-end AC drive applications", 39th Annual Conference of the IEEE Industrial Electronics Society (IECON'2013), 6010-6015 (2013).

[33] J. Rabkowski, S. Piasecki, and M. P. Kazmierkowski, "Design of a three-phase AC-DC converter with paralleled SiC MOSFETs", 16th International Power Electronics and Motion Control Conference and Exposition (PEMC), 533-539 (2014).

[34] S. Piasecki, J. Rabkowski, and M.P. Kazmierkowski, "Application of $25 \mathrm{~m} \Omega$ SiC MOSFETs in a $10 \mathrm{kVA}$ grid-connected AC-DC converter", 16th International Conference on Silicon Carbide and Related Materials (ICSCRM), 25-26 (2015). 